University of South Florida

DIGITAL COMMONS

Digital Commons @ University of

@ UNIVERSITY OF SOUTH FLORIDA

South Florida

Academic Resources Faculty and Staff

Publications

Tampa Library

June 2011

\title{
Coping with Hobgoblins: Rethinking Journals Processing in the E- Journals Environment at the University of South Florida
}

Carol Ann Borchert

University of South Florida, borchert@usf.edu

Follow this and additional works at: https://digitalcommons.usf.edu/tlar_pub

Part of the American Studies Commons, and the Library and Information Science Commons

\section{Scholar Commons Citation}

Borchert, Carol Ann, "Coping with Hobgoblins: Rethinking Journals Processing in the E-Journals Environment at the University of South Florida" (2011). Academic Resources Faculty and Staff Publications. 3.

https://digitalcommons.usf.edu/tlar_pub/3

This Article is brought to you for free and open access by the Tampa Library at Digital Commons @ University of South Florida. It has been accepted for inclusion in Academic Resources Faculty and Staff Publications by an authorized administrator of Digital Commons @ University of South Florida. For more information, please contact digitalcommons@usf.edu. 
Coping with Hobgoblins: Rethinking Journals Processing in the E-Journals Environment at the University of South Florida

Carol Ann Borchert

Acknowledgement

This paper is based on a presentation, "Re-Thinking Staff Resources in the E-Serials Environment," sponsored by the Continuing Resources Section of the Association for Library Collections and Technical Services at the ALA 2009 Annual Conference.

\section{Abstract}

Many libraries grapple with how to develop new skills for processing electronic journals, while still handling the print format as well. Journals in a print format have always been complex, and adding the electronic component has made them more so. Few libraries are adding staff to handle this workload. The University of South Florida Tampa Library has tried a number of workflow changes--not always successfully--to handle this transition. This paper will explore these changes, explaining why some were not successful and why others have resulted in efficiencies, and concludes with lessons learned that could benefit others.

Introduction $<1>$

Fifteen years ago, managing journals in print format was already a formidable challenge with changes in titles, publishers, frequency, size, and numbering. In an electronic environment, libraries have the added complications of negotiating license agreements, registering titles, and checking online access weeks or months after ordering. No physical volume arrives to indicate availability, and many libraries have no 
procedures for methodically checking in or claiming online journals. Libraries must be nimble to adapt to this new environment. Ralph Waldo Emerson observed that "A foolish consistency is the hobgoblin of little minds." Technical services departments can no longer afford foolish consistency. We must develop new and improved work processes that will benefit patrons. Anderson discusses the importance of patron-centered library processes in his article, "It's Not About the Workflow.", He states, "Where we once concerned ourselves primarily with serving patrons indirectly by following standards and setting up predictable, consistent workflows, we now must think in terms of serving them directly by being flexible and responsive to their changing needs." ${ }^{3}$ Purchasing material and then perfecting bibliographic records that patrons never read carefully or failing to make the information accessible in a usable way does not serve the patron. Libraries must move from library-centric to patron-centric practices. Librarians and staff in technical services can serve the patron well by reorganizing staff and workflows to optimize the patron's library experience.

Like many libraries, the University of South Florida (USF) Libraries struggle with the need to add new workflows and skill sets pertaining to e-resources while still managing the print collection. Staff in the journals processing area is not increasing for most libraries, yet this workload has increased with the electronic materials and requires new skill sets. Now that many institutions are facing budget cuts, staff size is shrinking rather than growing. In this transition to an electronic environment, many publications continue to be available only in print format. When staff members have worked comfortably in a print environment for decades, how do their time and skills transition to an online environment? The technical services staff in the USF Libraries is ever-shrinking, so they are finding ways to work with what they have.

This article will first examine the literature to see how other libraries have handled staff reorganizations to accommodate electronic resource workflows. After providing some background on the USF Libraries' environment and a brief summary of the 2004 workflow documentation project, this article will examine some of the attempts to restructure print and e-journal workflows. This will include 
the experiment to discontinue print journal check-in, discontinuation of binding, staff reorganization, and automation of many e-journal tasks.

Literature Review <1>

Many articles address attempts to manage the shift from print to electronic materials by eliminating or combining workflows for print journals or integrating electronic and print related tasks. Wayne State University formed an Electronic Resources Integration Task Force (ERITF) in 1998-1999, implementing a systematic approach to develop recommendations for handling e-resources. ${ }^{4}$ ERITF set cataloging priorities for free versus subscribed resources. Over time, the library created and filled three new positions - a Web librarian to handle access issues, an e-resources librarian, and a collection management officer. As of 2005, Wayne State provided full cataloging for subscribed and aggregator e-journal titles and provided e-journal access to patrons via the catalog, the library Website, Serials Solutions, and SFX.

Old Dominion University (ODU) in Virginia conducted a similar workflow analysis project to document recommendations for staff reallocations and target training needs for new skill sets. ${ }^{5}$ ODU's workflow analysis provided recommendations for altering the claiming and check-in processes, and increasing collaboration between the Serials Group and the Electronic Resources Cataloger. The Serials Coordinator, previously focused on print-related duties, began working more closely with electronic resources. ODU Libraries ultimately created a Serials and Electronic Resources Unit that coordinated extensively with the Electronic Resources Cataloger.

Initially Indiana University Libraries created a separate Electronic Resources Acquisitions Unit. However, they later chose to integrate the print and electronic functions, moving responsibility for managing both print and electronic journals into the Serials Acquisitions Unit. The Libraries used new management tools that have become available in recent years, such as e-resource management systems (ERMs), A-Z journal lists, and archive mechanisms such as LOCKSS. ${ }^{6}$ 
The Cushing/Whiting Medical Library at Yale University used a consultant who recommended discontinuing binding and check-in for journals. ${ }^{7}$ The library continued both activities, but shifted many print titles to electronic versions-form, thus reducing the time, money, and effort required to maintain the core print titles while refocusing those resources on the online collections. To prevent staff from reverting to just their print-related duties, they were assigned schedules for working on print and electronic journals: print tasks in the morning and electronic in the afternoon.

Montgomery and Sparks observed that, as a result of the shift from print to electronic at Drexel University, "it quickly became apparent that we were forcing fundamental changes in library operations. Almost no area of the library has been left untouched." ${ }^{8}$ This has proved true for many libraries. Any major changes in the focus of efforts in technical services are bound to impact public services. Discontinuing traditional print-related activity might complicate a few patrons' ability to find a print article in order to enhance many patrons' ability to find an electronic article. Anderson and Zink's article, "Implementing the Unthinkable," described how the University of Nevada-Reno (UNR) stopped checking in print journals to refocus staff time on e-resources. ${ }^{9}$ Because UNR spent more of the budget on ejournals and the e-journal usage was far outpacing that of the print, the UNR Library stopped devoting the majority of staff hours to processing print. The University of Nevada-Las Vegas (UNLV) took a different approach and conducted a series of journal assessment projects to determine which print titles could be cancelled in order to acquire more e-resources. ${ }^{10}$

\section{Background <1>}

The University of South Florida is a large research institution with nearly 30,000 FTE and a \$5.7 million materials budget. Of this, only $\$ 380,000$ is allocated for print journals, with $\$ 2.7$ million allocated for electronic journals, and an additional \$1.2 million allocated for other electronic resources (such as ebooks, databases, and data sets). The Academic Resources Department of the USF Libraries centrally manages electronic resources for USF St. Petersburg, USF Polytechnic in Lakeland, USF Sarasota, and 
the USF Tampa, Florida Mental Health Institute, and Health Sciences libraries on the Tampa campus. The Academic Resources Department also handles print journals for USF Tampa, USF Sarasota, USF Polytechnic, and the Florida Mental Health Institute Library. All USF campuses are on a single IP network. Managing the shift from print to electronic has resulted in several workflow projects over the past few years.

In 2003, USF faced a major impending change in workflows resulting from a move from the NOTIS telnet system to a Windows-based integrated library system (ILS), Aleph, scheduled for July 2005. At that time, the Interim Dean of the USF Libraries appointed a new Acting Director for Technology and Technical Services. Although the current Coordinator for Serials worked in the Reference Department at the time, the Acting Director knew she had a cataloging background and appointed her as chair of a team charged with examining and documenting all workflows, procedures, job descriptions, and methods of keeping statistics in the technical services area. The Technical Services Plan for Optimization and Productivity (TS Plan) team included all supervisors involved in technical services workflows plus the Coordinator of Electronic Collections, because these individuals had the best overview of departmental operations and the most authority to ensure that necessary information was documented. In addition to collecting information, the Acting Director asked the group to analyze the data and make recommendations for improving workflow efficiencies. The three main questions the group tried to keep in mind were: 1) what could we stop doing? 2) what were we not doing that we should? and 3) what could we do better?

The TS Plan group started meeting weekly in September 2003, creating a list of workflows that needed to be documented and a list of what the library was not doing due to a lack of money, staffing, training, or a need to shift priorities. After two full semesters, the TS Plan group produced a 99-page report for the Acting Director, Report of the Technical Services Plan for Optimization and Productivity, in June 2004. ${ }^{11}$ The resulting report educated the new director about technical services processes and standards and provided an overview for staff to determine if workflows were optimally efficient. With 
the impending move to a new ILS, this created a "snapshot" of workflows and procedures so that staff had a solid starting point in adapting to a new system.

The electronic resource workflow presented the biggest challenge. After implementing SFX as the USF Libraries' link resolver in mid-2003, many e-resource management issues pertained to the integrity of the SFX Knowledge Base. For instance, many of the generic dates listed in the SFX Knowledge Base (KB) did not reflect the years and volumes available specifically at USF. Also, catalogers were trying to keep up with new titles added to the SFX KB, an impossible task given the exponential increase in titles available through subscriptions, aggregator databases, and open access titles.

Because many of the issues highlighted in the TS Plan were related to e-journals, and because the Coordinator for Electronic Collections already suffered an overwhelming workload, the department created a Coordinator for Serials position in May 2004. Originally, the Coordinator for Serials reported to the Director of Technology and Technical Services (later the Director of Academic Resources). During a departmental reorganization in 2008, the Coordinator for Serials began reporting to the Coordinator of Electronic Collections. The purpose of this position was twofold: to have someone dedicated to handling serials issues full-time, and to pull the electronic journals workload from the Coordinator for Electronic Collections to allow her to focus on other aspects of e-resources. Over the past few years, there have been several attempts to organize and automate the electronic journal workflows, to reduce the print processing workload, and to free up staff time to work with electronic resources.

Changes in Journals Processing $<1>$

\section{Staffing Changes $<2>$}

The USF Libraries made some permanent changes in staffing even though the print workflows fluctuated dramatically. The department currently known as Academic Resources was formerly called Collection Analysis \& Technical Services, and, previous to that, Technology \& Technical Services. (figures 1-2) 
[insert figures 1-2 here.

Figure 1. Technology \& Technical Services Department, March 2004

Figure 2. Academic Resources Department, December 2009]

Since 2004, the Coordinator for Electronic Collections has accumulated a group of staff reporting directly to her. This includes 2.5 FTE librarians and one FTE staff member. The Coordinator for Electronic Collections oversees all e-resources and specifically manages databases, electronic books, and data sets. The Coordinator for Serials handles electronic journals. The Instructor Librarian for Electronic Resources handles a variety of duties, including e-resource cataloging, special projects, collection development, and database troubleshooting. The librarian assigned part-time to e-resources resides in the Reference Instruction \& Research Services Unit of Academic Services and focuses on gathering and presenting statistics. Like Indiana University Libraries did initially and as ODU did during their workflow analysis project, the USF Libraries have moved all electronic resource functions into a separate staff group. Indiana University Libraries moved away from this model later, reintegrating print and electronic functions into their Serials Acquisitions Unit. At this time, the USF Libraries have not made a similar transition.

The Serials Group, formerly Serials Acquisitions, has dwindled, but in some cases, the work as well as the people moved to the monographs side. In 2004, the USF Libraries had eight people in Serials: one supervisor, four Senior LTAs handling check-in, claiming, invoices, renewals and some e-resource functions, and one person each assigned to binding, government documents, and standing orders/serials. Standing orders and government documents are now handled from the monographs side, and the electronic resources are now handled by a full-time staff member reporting to the Coordinator for Electronic Collections. Formerly, the USF Libraries had a full-time e-resources cataloger, who recently retired and was not replaced. As of 2009, the Serials Group has three full-time staff members working 
with the Coordinator for Serials that handle check-in, renewals, invoices, ordering, and binding for print and electronic journals, and one of these also helps with SFX maintenance and e-journal registration.

\section{Print Journal Workflow <2>}

Print Journal Check-In<3>

The first attempt to streamline the print workflow occurred in the 2005/2006 fiscal year. Inspired by Anderson and Zink's discussion of UNR's decision to discontinue checking in print journal titles, the USF Libraries tested discontinuing print journal check-in for the USF Tampa Library. The discontinuation of print journal check-in was well-timed, because the data recording receipted unbound issues was lost in the move to the new ILS. This gave the staff a year to learn the new system before recovering that data, if the USF Libraries decided to return to check-in. The project lasted for one year, but the USF Libraries returned to a traditional check-in process. ${ }^{12}$ The test was not successful for several reasons. The print journal collection is arranged by call number, requiring staff in the Serials Group to look up call numbers even though they were not checking in materials. Also, the USF Libraries were still binding journals at that time; without receipt data, staff did not know when to pull a volume to bind it.

The Director for Academic Resources and the Coordinator for Serials hoped that discontinuing check-in would save staff time. In the previous system, checking in issues required typing the volume, issue, and date information for each title. The new ILS, Aleph, has a predictive check-in function lacking in the former system. The Serials Group ran a test to see how long using the new check-in features took and discovered that staff spent as much time not checking in materials as they would have been checking them in. In addition, not checking in issues caused frustration for both the technical and public services staff. The USF Libraries have not returned to daily newspaper check-in for the USF Tampa Library. Because this is a small group of titles housed at the Periodicals Desk, the staff member in that area can alert the Serials Group if a title becomes a delivery problem and needs to be claimed. 
In summer 2008, the Serials Group took a different approach and selected certain titles that would not be checked in. The library planned to create barcodes for titles that arrived fairly regularly with little history of problems, e.g., no claims or numbering changes. Staff would then scan the barcode to check in the item, freeing time to focus attention on the more difficult titles. However, all staff members in Serials were new employees at that time, so separating out the problem-free titles proved too complicated. The Serials Group abandoned the project by fall 2008.

\section{Binding $<3>$}

In fiscal year 2007/2008, the USF Libraries tried to selectively bind materials for the USF Tampa Library. Because the print collection is low-use and many of the titles are print plus online subscriptions, discontinuing binding probably would not have created a preservation problem for most titles. However, ceasing binding did cause workflow problems. At the USF Tampa Library, the current and bound materials existed in separate collection locations on the same floor, with the current journals area having a limited amount of shelf space. If the library was not going to bind, the unbound issues had to be integrated into the bound collection on a regular basis, usually at the end of a volume. These loose issues needed to be labeled in some way so that student shelvers knew to place the older unbound issues in the bound journals collection. Maneuvering around this roadblock required the same amount of staff time as binding, causing confusion and producing lower quality results. As long as the current and bound journals remained separate, discontinuing binding would not work. Ultimately, the USF Libraries returned to binding for all periodical titles.

The USF Libraries now bind only a very few high-use titles. This is more feasible because the two bound and unbound collections have been combined at the USF Tampa Library, which has the largest collection. Issues do not need to be moved and handled every few months. The directors made the decision to combine the current and bound periodicals after the earlier failed attempt at discontinuing binding and after evaluating just how little use the print collection receives. Maintaining two separate 
shelving areas created a lot of work while benefitting just a few patrons. This also reduces the work necessary when the USF Libraries convert titles to online or cancel them. Previously, staff had to hold a processing slip for a cancelled or converted title for several months until the final issue arrived. The slips serve as reminders that something still needs to be done to a particular title, in this case, to handle the final issues. With selective binding, staff will be able to leave the unbound issues on the shelf next to the older bound issues.

Electronic Journal Workflow <2>

Because the Academic Resources Department could not further streamline the handling of print journals, the department focused on improving workflow efficiencies for electronic journals. The Assistant Director for Academic Resources has a strong computer and technical background, and she continuously reviews procedures to find ways to automate laborious and repetitive processes. With her help, the Academic Resources Department tries to maximize the effectiveness of the systems being used, learning new ways to extract and input data from and into library systems. USF has made changes in several areas to more effectively manage electronic resources.

Acquisitions <3>

In the area of acquisitions, the USF Libraries use electronic data interchange (EDI) invoicing for both journals and monographs when possible and utilize macros to create multi-line invoices when journal vendors do not offer EDI invoicing. The EDI invoices from the subscription agents load into Aleph through an automated process. The Coordinator for Serials briefly examines the invoice in Aleph to ensure that all invoice lines loaded with a fund code attached to them, and that no charges have been applied to closed or cancelled records. A staff member then checks each line to ensure that everything loaded properly on the correct titles with no duplicate or overlapping payments. 
The USF Libraries pay most large e-journal packages directly instead of through a subscription agent. For packages that still have multi-line invoices, the Coordinator for Serials uses a macro to create the invoice and invoice lines. The macro generates the invoice in Aleph, then pulls information from a spreadsheet created by a staff member to populate the invoice lines. The spreadsheet contains the title, ILS order number, price, and subscription dates. The macro copies that information into Aleph to generate the invoice lines. One problem is that the current version of Aleph has frames within the application window which slow down the macro program. To increase efficiency and eliminate the need for this macro process, the Coordinator for Serials is moving the remaining multi-line invoices paid directly to publishers to be paid on package-level records as single-line invoices. Spreadsheets provided by the publishers during the renewal process back up the invoices, showing which titles the USF Libraries have as subscriptions and the cost of each. This will save time in approving the invoice for payment and avoid having to close and open title-level orders when titles move from one package to another. Paying at the package level has not proved to be a burden. Because many titles are acquired as part of USF's consortial packages, the Coordinator for Serials pulls title lists from SFX, not from the catalog. This better reflects the titles available to USF based on our subscriptions when the librarians need to compile information for the directors or for accreditation reports.

Registering Titles and Providing Access <3>

The 2004 TS Plan document contained a draft of a processing slip for e-resources and e-journals. Because the library had no e-resource management system, and e-resources have no physical presence to remind staff to process them, the processing slips provided a physical reminder to show where a resource stood in the process of being made available for public use. Prior to 2003, the USF Libraries had no cohesive workflow for electronic journals, with each title or group of titles treated on a case-by-case basis. A few e-journal subscriptions had been paid but were not activated or made accessible to patrons. The processing slips corrected this issue. The Coordinator for Serials and the Coordinator for Electronic 
Collections later decided that e-journals had enough variation from other types of e-resources to merit a separate processing slip. The e-journals processing slip, attached to a bright orange folder, travels from one area to the next for licensing, ordering, registration, and batch download of bibliographic records.

[insert figure 3 here:

Figure 3. Electronic Journal Processing Slip]

For large packages, the Coordinator for Serials uses the Dataloader feature in SFX whenever possible, loading publisher-provided spreadsheets containing local holdings information. The Coordinator for Serials reviews the spreadsheet, formats the holdings lines, performs a test run, then loads the data and fixes errors. Previously, a full-time staff member checked the access for each title in a large subscription package by opening several articles in various issues to determine the earliest and most recent issues available. Now, the Coordinator for Serials uses the Dataloader to review all holdings data for a major package, format the data, test it, and load holdings information for the entire group of titles in one to two hours. For some packages, a staff member still needs to check for access title by title, but being able to load groups of titles has been a time-saver, allowing patrons to access material much more quickly.

Electronic Journal Cataloging <3>

The USF Libraries Cataloging Policy Committee decided a few years ago to link e-journal records in the catalog to SFX instead of to individual publisher sites. As a result, librarians only adjust dates of access in SFX, instead of maintaining duplicate information in the catalog and updating links as titles moved from publisher to publisher. This decision saved time in maintaining the holdings data in two places, and the links in the catalog remain the same, even when the titles move from one subscription package to another. 
In 2007, the USF Libraries instituted the MARCit! service from SFX to load bibliographic records based on our SFX holdings. Formerly, a single cataloger tried to do full-level cataloging for individual journal titles. As electronic subscription titles proliferated, and the USF Libraries joined Big Deal packages — which provide access to a large bundle of titles based on a set group of subscribed titles - the Electronic Resources Cataloger was overwhelmed. Implementing MARCit! eliminated the backlog of e-journal titles awaiting cataloging. The USF Libraries can now load titles from aggregator databases and free e-journal targets. The main problem is finding a way to synchronize SFX and Aleph without a major effort on the part of the person loading the records. Adding new titles is not problematic, but determining which titles should be removed from the catalog is. When Ex Libris removes a title from a title group in the SFX KB, the entire bibliographic record should not necessarily be removed from the ILS system. That title might still be active in another database or through an open access site. Because the MARCit! records are CONSER print records adapted to look like electronic records, the USF Libraries overlay on an SFX system-generated number in the bibliographic record's 035 (system control) field, not on the OCLC number or ISSN number. This way, new MARCit! e-journal bibliographic records do not overlay existing records for print journals.

\section{Administration of Electronic Journals $<3>$}

To replace the former database management system, the USF Libraries created an in-house ERM in the form of an unnamed Access database in fall 2004, but the ERM has not been altered since that time. The ERM provided a central place to list resources, contact information, administrative logins, and methods of gathering statistics. The ability to input additional data such as licensing terms exists, but staff members working with e-resources have not had time to make this a priority. After using the system for a year, the Electronic Resources Group evaluated the Access database and suggested numerous revisions, but the original creator of the Access database ERM had moved on to other assignments and never implemented the requested revisions. The USF Libraries continue to use paper processing slips for all forms of 
electronic resources. The Electronic Resources Group is actively seeking a replacement system for the processing slips and the in-house Access database ERM.

Supporting Patrons <3>

For the past several years, the USF Libraries have been using ticketing systems to support patrons and public services in accessing electronic journals. ${ }^{13}$ Previously the Academic Resources Department used a commercially-produced customer relations management system, but transitioned to an in-house system tailored to local needs. Because no one was upgrading or maintaining the in-house system, the Academic Resources Department has returned to a commercially-produced system called RightNow as of 2010. Using this system, which is also used for the e-mail Ask-A-Librarian service at USF, patrons fill out a form to indicate they are having a problem accessing an e-journal title, providing a sample citation and a brief description of the problem. All staff members who work with that type of form receive an email notification that an incident, or ticket, has been submitted to the system. A librarian or staff member logs into the system and responds to the issue. Other staff members can see the response and any notes pertaining to the status of the problem. Once an incident is solved, the ticket is closed and does not display in the list with the open tickets. These systems allow library staff to search previous problem reports, to better track patterns of problem reports, and to easily view a list of all reported problems still in process and the current status. Staff members who are learning to handle e-journal access issues can see all communications with the patron and any internal notes outlining the underlying issue and method of resolution.

\section{Quality Control in SFX <3>}

In SFX, as in the catalog, staff efforts focus on managing the subscription titles rather than free material. For open access and aggregator titles, the library relies on Ex Libris to maintain the accuracy of the SFX 
Knowledge Base. Patrons, staff, and librarians report problems through the ticketing system to notify the Coordinator for Serials of an access problem. The USF Libraries also altered the SFX screen display to facilitate use and selection of full-text options in the SFX display. The Assistant Director for Academic Resources reorganized the public screen in SFX to display subscription groups at the top of the screen, and aggregator and free online sites in the lower portion of the screen. This directed patrons to sites with more complete article coverage, which are also the title groups that are the staff's focus for maintenance and quality control.

To facilitate reporting problems, the SFX screen has a link to the report form to submit problems through the ticketing system. One staff member at the Periodicals Desk of Academic Services checks SFX regularly and reports problems to the Coordinator for Serials via the ticketing system before patrons find them. This is a very informal system of evaluating and monitoring success in handling electronic journals. Some weeks staff members in public services report no problems; sometimes they report several issues. The serials librarian in the USF Shimberg Health Sciences Library also uses the form to report discontinued, reinstated, or new subscriptions. USF's electronic journal usage through SFX is so high that our statistics must be archived every few months to keep the system from crashing during the monthly update process. Considering this high usage, the library receives very few problem reports, and most of those are from the open access and aggregator targets that staff members do not locally maintain.

Prioritizing and Alleviating Existing Workloads <2>

The USF Libraries have explored several options for rearranging workloads and priorities in view of increasing responsibilities and shifting staff levels. In the absence of a full-time electronic resources cataloging position, the library recently discontinued cataloging free Websites. Though some of the public services librarians were not happy with this decision, most understood the need to focus staff time on the Libraries' subscribed resources, and many realized that patrons will find those free sites via Google, rather than through the library Website. Because the library no longer has a full-time cataloger 
for electronic resources, trying to catalog various Websites of interest and maintain the links has proven too time-consuming. A librarian is handling e-resource cataloging part-time, in addition to other duties. New e-journals are handled through MARCit! and new e-books are handled through MARCit!, vendor record loads, or OCLC record batch loads. This leaves databases as the main items requiring individual cataloging.

USF has a large commuter population, and though the print journal use is minimal as observed by public services staff and student shelvers in the Periodicals collection, the e-journal use is extremely high. Evaluating e-resource use shows that the only resources that have low usage statistics are specialized, high-impact research resources. For this reason, the USF Libraries have made a concerted effort to convert print resources to online whenever publishers can assure perpetual access. As a result, the USF Libraries subscribe to around 2,000 print journal titles. The USF Libraries have also cancelled many print titles, mostly at the USF Tampa Library. Cancelling print titles was not only a means to save staff time on processing. Like University of Nevada-Las Vegas, cancelling low-use print also helped fund new journals that would better serve patron research needs, many of which had online content. In 2008, the collection development librarians at USF conducted a survey of the faculty to determine which print titles could be cancelled due to low research value or interest. The collection development librarians approved 223 low-use titles for cancellation during a budget crisis. During the survey, faculty had the opportunity to list titles they needed which were not in the USF Libraries' collection. The USF Libraries purchased twenty-five new print or print plus online subscriptions and twenty-nine new online-only subscriptions in 2009. The Coordinator for Collections and the Coordinator for Serials are currently evaluating for cancellation all remaining print titles that are ephemeral, are retained for a limited time, are more than three years late in arriving, or have a history of claiming problems. By making the low-use print collection as lean as possible, staff will be better able to service the electronic collection.

\section{Conclusion $\langle 1\rangle$}


The USF Libraries are finding new solutions to old and new problems working in the fast-paced e-journal environment. Not all of these solutions prove ideal, but it is perhaps better to fail than to simply not try. Accepting the status quo is not an option, particularly with an ever-shrinking staff. Through these various changes, the Academic Resources Department of the USF Libraries has learned several valuable lessons:

- Be flexible and dynamic. The USF Libraries have experimented with several workflow ideas to discover what works - and what does not. Technology and patron expectations are constantly evolving, and libraries must be nimble and willing to adapt.

- Encourage innovation. The Director of Academic Resources encourages the librarians and staff to try new methods, allowing the autonomy to implement new ideas. Such ideas have included discontinuing check-in and binding, automating workflows, and implementing an online ticket system.

- Automate when possible. Electronic resources are expanding at an astounding rate, and the university cannot fund enough staff to handle this manually. The USF Libraries have been automating workflows in an attempt to keep pace with the growth in online collections.

- Be willing to let things go. The face of research is changing, and some processes that were once important no longer are - at least not to our patrons. The USF Libraries have seen evidence of this in the dwindling use of the print collection. Libraries must change or face increasing marginalization in the research community.

- Pay attention to what patrons need now. Weigh that against "how we've always done it." The disconnect between these two items is expanding. USF offers many online classes, which means many students do not regularly visit campus. The library must shift resources in order to best serve patrons at their point of need.

- Focus on users and align priorities accordingly. Libraries cannot do everything anymore. What is the most important task today that will have the highest service impact for patrons? For USF, this means more online resources and services. 
- Get support from supervisors and staff alike. The supervisors will be doing the training to move staff into the $21^{\text {st }}$ century — or not. Staff members must bring their technical abilities current with today's needs. Having a few people in the Academic Resources Department automate e-resource workflows has allowed the remaining staff some time to bring their skills current.

- If a process is not working, stop, re-evaluate and be willing to choose a different course of action. The USF Libraries are continuously evaluating new and old ways of handling technical services processes.

As a result of the various changes in workflow detailed in this article, the USF Libraries have improved the integrity of SFX and e-journal data available to patrons. These changes also resulted in a significant increase in the number of titles available to patrons. The use of MARCit! has eliminated the cataloging backlog for e-journals, and librarians and staff can now activate titles faster as well as make the associated bibliographic records available more quickly in the catalog. The USF Libraries continue to move from print to online whenever and as quickly as possible. Currently, USF has 11,000 electronic subscriptions and around 2,000 print subscriptions, and provides access to tens of thousands of aggregator and open access titles. By paying packages directly, the USF Libraries save money on service charges. These changes have greatly facilitated handling a larger e-journal workload with fewer people—a necessity in the current budget environment. By remaining open to new ways of managing resources, we are dispelling Emerson's hobgoblins. We continue to learn where we need to be consistent with our old work methods, and where innovation is not only possible, but wise. 


\section{References}

1. Ralph Waldo Emerson, "Self-Reliance," Selected Writings of Ralph Waldo Emerson, ed. William H. Gilman (New York: New American Library, 2003), 273.

2. Rick Anderson, "It's Not About the Workflow: Patron-Centered Practices for the $21^{\text {st }}$ Century," The Serials Librarian 51, no. 3/4 (2007): 189-199. http://dx.doi.org/10.1300/J123v51n03_13 (accessed Dec. 23, 2009)

3. Ibid., 190.

4. Richard P. Jasper and Laura Sheble, "Evolutionary Approach to Managing E-Resources," The Serials Librarian 47, no. 4 (2005): 4, 55-70. http://dx.doi.org/10.1300/J123v.47n04_07 (accessed Nov. 12, 2009)

5. Tonia Graves and Michael Arthur, "Developing a Crystal Clear Future for the Serials Unit in an Electronic Environment: Results of a Workflow Analysis," Serials Review 32, no. 4 (2006): 238-246. http://dx.doi.org/10.1016/j.serrev.2006.09.003 (accessed Dec. 23, 2009)

6. Lynda Fuller Clendenning, "Biz of Acq: Mainstreaming 'E': Integrating Print and Electronic Journal Acquisitions and Management ," Against the Grain 18, no. 2 (2006): 66-68.

7. Daniel M. Dollar, et al., "Realizing What's Essential: A Case Study on Integrating Electronic Journal Management into a Print-Centric Technical Services Department," Journal of the Medical Library Association 95, no. 2 (2007): 147-155, http://dx.doi.org/10.3163/1536-5050.95.2.147 (accessed Nov. 12, 2009).

8. Carol Hansen Montgomery and JoAnne L. Sparks, "The Transition to an Electronic Journal Collection: Managing the Organizational Changes," Serials Review 26, no. 3 (2000): 5. http://dx.doi.org/10.1016/S0098-7913(00)00073-3 (accessed Nov. 12, 2009)

9. Rick Anderson and Steven Zink, "Implementing the Unthinkable: The Demise of Periodicals CheckIn at the University of Nevada," Library Collections, Acquisitions \& Technical Services 27, no. 1 (2003): 61-71. http://dx.doi.org/10.1016/S1464-9055(02)00309-3 (accessed Dec. 23, 2009) 
10. Xiaoyin Zhang and Michaelyn Haslam, "Movement Toward a Predominantly Electronic Journal Collection," Library Hi Tech 23, no. 1 (2005):82-89. http://dx.doi.org/10.1108/07378830510586720 (accessed November 12, 2009)

11. Carol Ann Borchert, et al. "Technical Services Plan for Optimization and Productivity." ([USF Libraries], 2004), http://purl.fcla.edu/usf/dc/u24.60 (accessed Dec. 23, 2009)

12. Carol Ann Borchert, “To Check In or Not To Check In? That is the Question,” Serials Review 33, no.4 (2007):238-243. http://dx.doi.org/10.1016/j.serrev.2007.08.010 (accessed Dec. 23, 2009)

13. Carol Ann Borchert. "Untangling the Jungle of E-Journal Access Issues Using CRM Software." Library Collections, Acquisitions and Technical Services 30, no.3/4 (2006):224-237. http://dx.doi.org/10.1016/j.lcats.2006.10.002 (accessed July 9, 2010) 
Figure 1. Technology \& Technical Services Department, March 2004
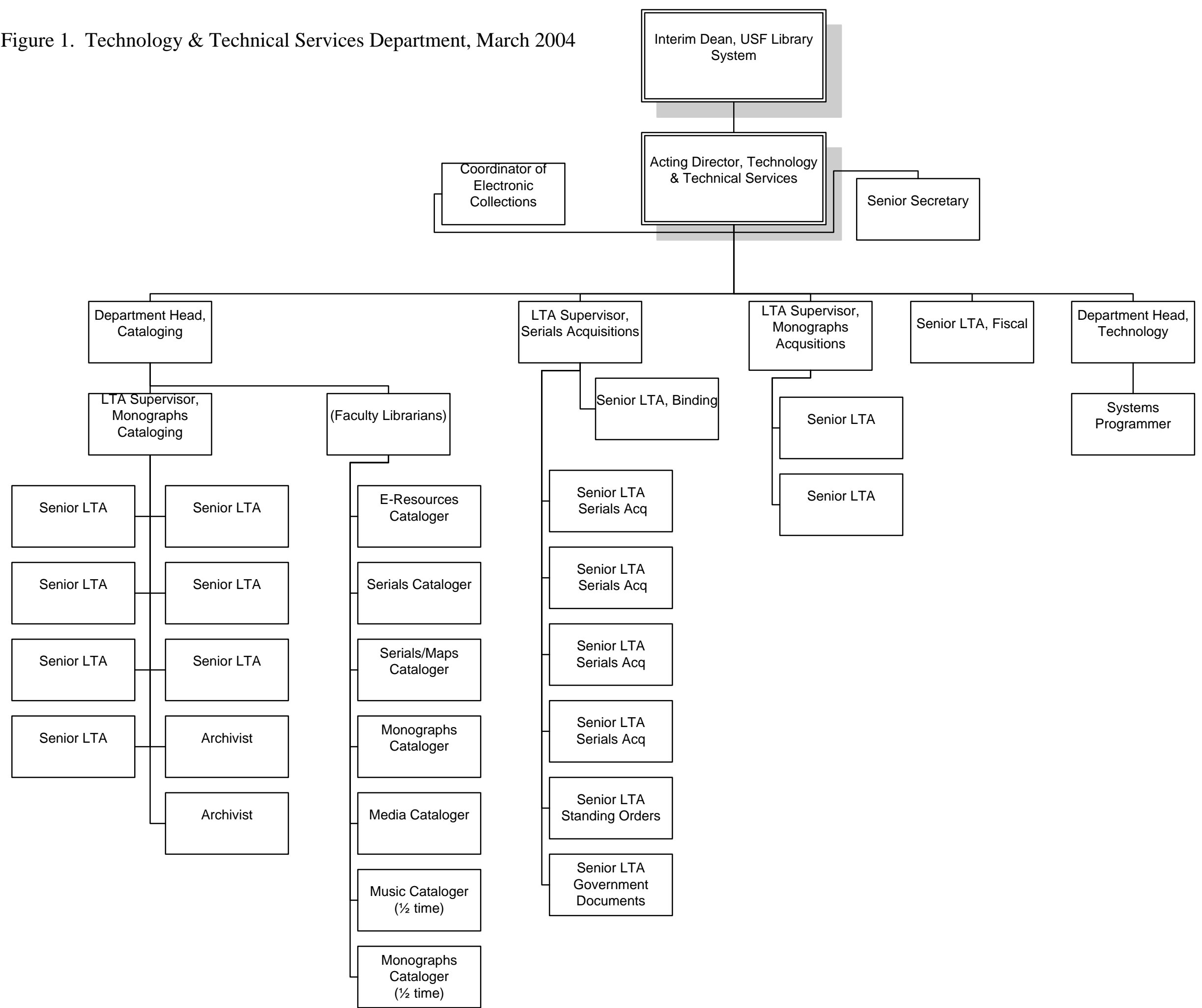
Figure 2. Academic Resources Department, December 2009

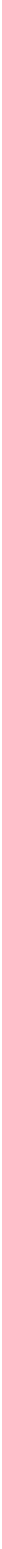


Figure 3. Electronic Journal Processing Slip.

\section{ELECTRONIC JOURNAL PROCESSING SLIP}

\section{Title/Group:}

\section{COORDINATOR FOR SERIALS}

started: forwarded:

original requestor:

- license agreement is complete

- no user agreement is necessary

vendor name:

○ previous account:

- NEW account:

- NEW title number:

contact person:

contact email/phone \#:

- consortial subscriber

- institutional subscriber

- must retain _ print or __multiple subscriptions to keep online access

account/customer number:

$\circ$ this is a subscription group; spreadsheet of titles is on the department $\mathrm{T}: \backslash$ drive and a title list is inside folder

o this is a __ single title or titles

payment: budget code

- NEW online-only journal

- Print plus Online subscription

- CONVERT print subscription to online only

SFX Target name:

○ target has been activated

- threshold should be:

- ISSN\#

source of use statistics:

$\circ$ database management information entered in Access database
ORDERING received:___ forwarded:

O order has been placed; order set up

ALEPH Order \#

- sent new ILS number and HEGIS/fund code to vendor

- if moving online only, fill out Converted to Online Only Print Cancellations form

- invoice received, info verified \& corrected as necessary; keyed into LMS

\section{REGISTERING received: forwarded:}

- registration is completed (provided vendor with IP address range, USF contact information, etc.)

○ username/password entered in Access database

- publisher has notified USF that the title is accessible

- vendor link has been checked for accessibility and subscription year content

○ send email to help@usf.edu to have them enter the URL in the proxy server

- SFX object has been activated

\section{ASSOC DIRECTOR OF ACADEMIC RESOURCES}

MARCit!:

- exported MARCit! record to ALEPH

COORDINATOR FOR SERIALS received:

$\circ$ notify original requestor 